\title{
Peroxynitrite induces F-actin depolymerization and blockade of myosin ATPase stimulation
}

\author{
Teresa Tiago a, Susana Ramos ${ }^{\text {a }}$, Manuel Aureliano a , Carlos Gutiérrez-Merino ${ }^{\text {b,* }}$ \\ ${ }^{a}$ Centre for Marine Sciences (CCMar), Depto. de Química e Bioquímica, FCT, Universidade do Algarve, 8005-139 Faro, Portugal \\ b Depto. Bioquímica y Biología Molecular, Facultad de Ciencias, Universidad de Extremadura, 06071-Badajoz, Spain
}

Received 22 January 2006

Available online 31 January 2006

\begin{abstract}
Treatment of F-actin with the peroxynitrite-releasing agent 3-morpholinosydnonimine (SIN-1) produced a dose-dependent F-actin depolymerization. This is due to released peroxynitrite because it is not produced by 'decomposed SIN-1', and it is prevented by superoxide dismutase concentrations efficiently preventing peroxynitrite formation. F-actin depolymerization has been found to be very sensitive to peroxynitrite, as exposure to fluxes as low as $50-100 \mathrm{nM}$ peroxynitrite leads to nearly $50 \%$ depolymerization in about $1 \mathrm{~h}$. G-actin polymerization is also impaired by peroxynitrite although with nearly 2-fold lower sensitivity. Exposure of F-actin to submicromolar fluxes of peroxynitrite produced cysteine oxidation and also a blockade of the ability of actin to stimulate myosin ATPase activity. Our results suggest that an imbalance of the F-actin/G-actin equilibrium can account for the observed structural and functional impairment of myofibrils under the peroxynitrite-mediated oxidative stress reported for some pathophysiological conditions.
\end{abstract}

(C) 2006 Elsevier Inc. All rights reserved.

Keywords: F-actin; Peroxynitrite; Myosin ATPase; Actin polymerization/depolymerization; Oxidative stress; SIN-1; Cysteine oxidation

Exposure of muscle cells to chronic oxidative stress conditions results in impairment of muscle contraction, which has been proposed to be, at least in part, the result of oxidative modification of myofibril proteins [1,2]. On the other hand, it has been shown that $\mathrm{Cys}_{374}$ of actin monomer (G-actin) is particularly sensitive to oxidation by hydrogen peroxide [3] and nitric oxide donors [4], which are stress conditions leading to a reduction of the actin polymer (F-actin), that plays a major role in myofibril contraction. Peroxynitrite is an important oxidative stress agent in ischemia/reperfusion insults, such as heart infarct or atrial fibrillation [1,5,6], and inflammation [7], and it has been

\footnotetext{
Abbreviations: DSC, differential scanning calorimetry; DNPH, 2,4dinitrophenylhydrazine; DTNB, 5,5'-dithio-bis(2-nitrobenzoate); IC $_{50}$, inhibitor concentration required to produce $50 \%$ inhibition; S1, myosin subfragment 1; SIN-1, 3-morpholinosydnonimine; SOD, superoxide dismutase; Tris, tris(hydroxymethyl)aminomethane hydrochloride; U, amount of enzyme that releases $1 \mu \mathrm{mol}$ product per minute.

* Corresponding author. Fax: +34 924289419.

E-mail address: carlosgm@unex.es (C. Gutiérrez-Merino).
}

reported that peroxynitrite can inhibit actin polymerization in neutrophils [8]. Furthermore, in aged muscle, actin is one of the proteins showing higher content of the commonly used fingerprint marker of peroxynitrite-reactive proteins 3-nitrotyrosine [9]. During inflammation and ischemia/reperfusion episodes tissue cells are exposed to fluxes of peroxynitrite ranging from submicromolar to micromolar concentrations $[7,10]$. SIN-1 is being used to mimic the effects of chronic exposure of cells in culture to a peroxynitrite oxidative stress [11,12], because it slowly decomposes in neutral and weakly alkaline aqueous solutions releasing nitric oxide and superoxide anion [13], which react with each other to produce peroxynitrite with a second order rate constant of (4-7) $\times 10^{9} \mathrm{M}^{-1} \mathrm{~s}^{-1}$ close to the diffusion limit for chemical reactions $[10,14]$. Moreover, the kinetics of peroxynitrite generation and the peroxynitrite concentration attained in the solution during SIN-1 decomposition can be reliably monitored in the buffered solutions commonly used for biochemical studies with isolated subcellular components [15]. 
In this work, we report that exposure to submicromolar fluxes of peroxynitrite, during $2 \mathrm{~h}$, produces an extensive F-actin depolymerization that leads to an almost complete inhibition of myosin ATPase activity stimulation.

\section{Materials and methods}

Protein purification. Actin was extracted from acetone powder of rabbit skeletal muscle in buffer $\mathrm{G}$ [2 mM Tris, $\mathrm{pH} 8.0,0.2 \mathrm{mM}$ ATP, $0.2 \mathrm{mM} \mathrm{CaCl}, 0.5 \mathrm{mM} \quad \beta$-mercaptoethanol, and $\left.0.005 \% \mathrm{NaN}_{3}\right]$ as described by Pardee and Spudich [16]. G-actin $\left(\mathrm{M}_{\mathrm{r}} 42.3 \mathrm{kDa}\right)$ concentration was determined by measuring the absorbance at $290 \mathrm{~nm}$ using an extinction coefficient of $0.617 \mathrm{mg}^{-1} \mathrm{~mL} \mathrm{~cm}^{-1}$ [17]. Myosin subfragment-1 (S1) has been prepared as indicated in Tiago et al. [18]. S1 ( $\left.\mathrm{M}_{\mathrm{r}} 115 \mathrm{kDa}\right)$ concentration was determined spectrophotometrically by using an extinction coefficient of $E_{280}^{1 \%}=7.5 \mathrm{~cm}^{-1}$

SIN-1 treatments on actin. Actin samples $(2 \mu \mathrm{M})$ were incubated with various concentrations of SIN- 1 at $25^{\circ} \mathrm{C}$ for $2 \mathrm{~h}$, a time in which more than $95 \%$ of peroxynitrite derived from SIN-1 decomposition had already been released [15], in $10 \mathrm{mM}$ Tris ( $\mathrm{pH} 8.5$ ), $25 \mathrm{mM} \mathrm{KCl}$ for F-actin and in $10 \mathrm{mM}$ Tris (pH 8.5), $0.2 \mathrm{mM}$ ATP, and $0.2 \mathrm{mM} \mathrm{CaCl}_{2}$ for G-actin.

Light scattering measurements. F-actin depolymerization and G-actin polymerization were followed at $25^{\circ} \mathrm{C}$ by changes in the light scattering intensity monitored at $90^{\circ}$ with respect to the incident light, with both monochromators set at $546 \mathrm{~nm}$ [19], using a Perkin Elmer 650-40 spectrofluorimeter. To minimize error noise in a second series of experiments, the monochromators were set at $500 \mathrm{~nm}$ (excitation) and $510 \mathrm{~nm}$ (emission), and after intensity normalization both approaches gave the same results for F-actin depolymerization.

Measurement of F-actin stimulated $\mathrm{S} 1 \mathrm{Mg}^{2+}$-ATPase activity. The stimulation of myosin $\mathrm{S} 1 \mathrm{Mg}^{2+}$-ATPase activity by $\mathrm{F}$-actin was measured spectrophotometrically at $25^{\circ} \mathrm{C}$ in the buffer of SIN-1 treatment using the coupled enzyme pyruvate kinase/lactate dehydrogenase $(0.42 \mathrm{mM}$ phosphoenolpyruvate, $0.375 \mathrm{mM}$ NADH, $18 \mathrm{U}$ of lactate dehydrogenase, and $18 \mathrm{U}$ of pyruvate kinase), as in Tiago et al. [18].

Measurements of cysteine oxidation, 3-nitrotyrosine formation, and protein carbonyls. The titration of actin cysteines was done with DTNB, as indicated in previous works [20,21], using an extinction coefficient at $412 \mathrm{~nm}$ of $13,200 \mathrm{M}^{-1} \mathrm{~cm}^{-1}$ for the coloured product thionitrophenolate. The extent of nitrotyrosine formation was measured spectrophotometrically, using an extinction coefficient at $415 \mathrm{~nm}$ of 4560 and $4320 \mathrm{M}^{-1} \mathrm{~cm}^{-1}$, determined from measurements of pure 3-nitrotyrosine solutions prepared by weight in the buffer used for the treatment with SIN1 of F-actin and G-actin, respectively. Protein carbonyl formation was measured spectrophotometrically using DNPH as in Dalle-Donne et al. [22]. Carbonyl content in actin samples was estimated by measuring the absorbance at $366 \mathrm{~nm}$ using a molar absorption coefficient of $22,000 \mathrm{M}^{-1} \mathrm{~cm}^{-1}$.

Differential scanning calorimetry measurements. DSC measurements were done as described in Merino and Gutiérrez-Merino [23]. Briefly, scanning calorimetry measurements were carried out using a differential scanning calorimeter MicroCal MC-2, operated at a scanning rate of $60{ }^{\circ} \mathrm{C} \mathrm{h}^{-1}$ and under a nitrogen pressure of $1.5-2 \mathrm{~kg} \mathrm{~cm}^{-2}$ during the scan. To minimize the $\mathrm{pH}$ change during the temperature scan, due to the large enthalpy of protonation of Tris, the buffer used for F-actin treatments with SIN-1 was supplemented with $50 \mathrm{mM}$ phosphate $(\mathrm{pH}$ 7) before loading the samples in the DSC. The analysis of the calorimetric data was carried out with the Origin ${ }^{\mathrm{TM}}$ software developed by MicroCal (Northampton, MA, USA). The curve fitting used Marquadt methods based on non-linear least-squares, being improved the guesses for each parameter using an iterative process until there is no further improvement of the fit (minimum $\chi^{2}$ value).

Chemicals. Chemicals used to prepare buffers were reagent grade. ATP, ADP, DNPH, DTNB, NADH, 3-nitrotyrosine, phosphoenolpyruvate, and SIN-1 were supplied by Sigma Chemical Co. (St. Louis, MO, USA). Pyruvate kinase and lactate dehydrogenase were purchased from Roche Molecular Biochemicals (Mannheim, Germany). 'Decomposed
SIN-1' was prepared leaving a solution of SIN-1 (1-10 mM) in buffer $10 \mathrm{mM}$ Tris and $25 \mathrm{mM} \mathrm{KCl}(\mathrm{pH} 8.5)$ to stand at room temperature for $12 \mathrm{~h}$.

\section{Results and discussion}

Exposure to submicromolar peroxynitrite generated during SIN-1 decomposition promotes F-actin depolymerization and inhibits F-actin stimulated myosin S1-ATPase activity

Treatment of F-actin with SIN-1 resulted in a strong stimulation of the kinetics of $\mathrm{F}$-actin depolymerization (Fig. 1A). As the intensity of light scattering of F-actin solutions was found to be linearly dependent upon F-actin concentration up to $9 \mu \mathrm{M}$ F-actin (data not shown), the change of light scattering intensity can be converted in percent of polymerized F-actin taking into account the intensity signal of G-actin (Fig. 1A). The extent of F-actin depolymerization after complete decomposition of SIN-1 (i.e., after $2 \mathrm{~h}$ exposure to SIN-1) is dependent upon SIN-1 concentration (Fig. 1B), yielding an $\mathrm{IC}_{50}$ value of $4.5 \pm 0.5 \mu \mathrm{M}$ SIN-1, i.e., approximately two moles SIN-1/mole of F-actin monomer. In addition, the onset of the kinetics of F-actin depolymerization is shortened as the SIN-1 concentration rises, due to the stimulation of the maximum rate of $\mathrm{F}$-actin depolymerization, as shown by the increase of the maximum slope of the light scattering decay traces in Fig. 1A. The effects of SIN-1 on F-actin depolymerization are due to the short-lived peroxynitrite produced during SIN-1 decomposition, because: (i) they are not produced by 'decomposed SIN-1', (ii) SOD, which efficiently scavenges $\mathrm{O}_{2}{ }^{-}$before reacting with $\mathrm{NO}^{\circ}[12,15]$, and $\mathrm{SOD}$ plus catalase (to remove $\mathrm{H}_{2} \mathrm{O}_{2}$ released by SOD activity) blocked the effect of exposure to SIN-1 on F-actin depolymerization (Fig. 1C), and (iii) hydrogen peroxide produced during SIN-1 decomposition in the buffer used in these experiments was lower than $0.5 \mu \mathrm{M}$ and catalase did not prevent against the depolymerization of F-actin by exposure to SIN-1 (results not shown). From the kinetics of peroxynitrite production during SIN-1 decomposition under these experimental conditions [15,24] it follows that: (1) exposure of $\mathrm{F}$-actin to peroxynitrite fluxes as low as $50-100 \mathrm{nM}$ during $1-2 \mathrm{~h}$ produced nearly $50 \%$ F-actin depolymerization, and (2) the $\mathrm{IC}_{50}$ for F-actin depolymerization takes place at a molar ratio of peroxynitrite/actin monomer close to 2 .

Moreover, the extent of F-actin depolymerization induced by peroxynitrite is sufficient to produce blockade of myosin $\mathrm{S} 1 \mathrm{Mg}^{2+}$-ATPase activity stimulation by F-actin with an $\mathrm{IC}_{50}$ of $20 \pm 2 \mu \mathrm{M}$ SIN-1 (Fig. 2), thus, pointing out that $\mathrm{F}$-actin depolymerization induced by peroxynitrite can inhibit myofibril actomyosin ATPase activity. Therefore, exposure to peroxynitrite is eventually impairing G-F actin equilibrium inducing shortening of the actin filaments to a size smaller than that needed to activate myo$\sin$ S1 ATPase. 
A

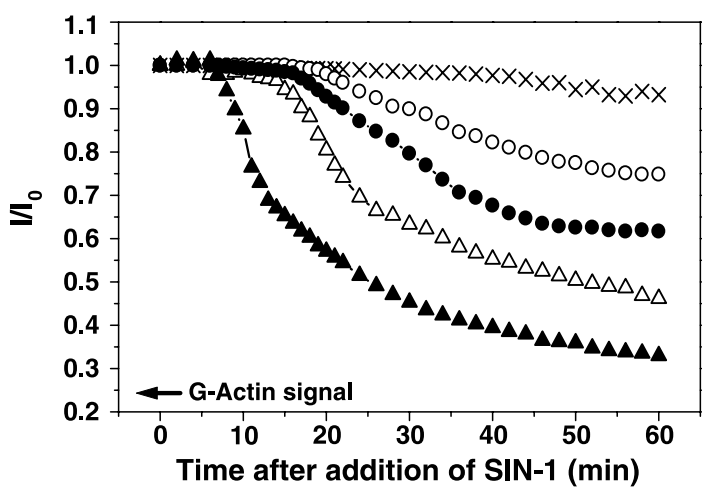

B

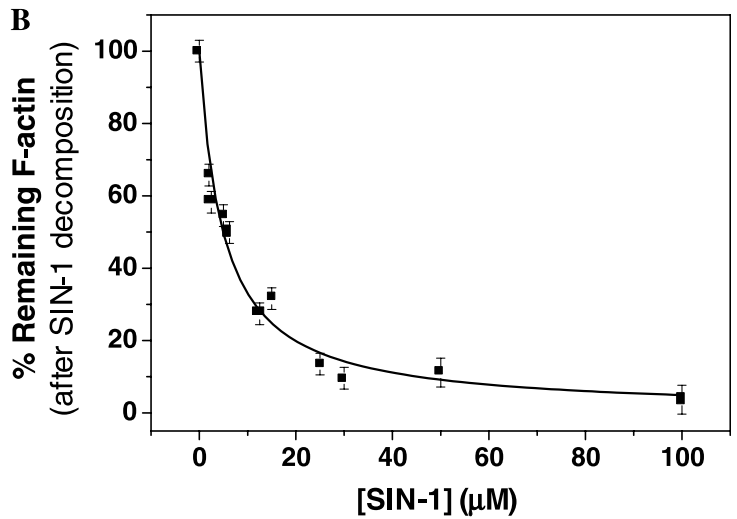

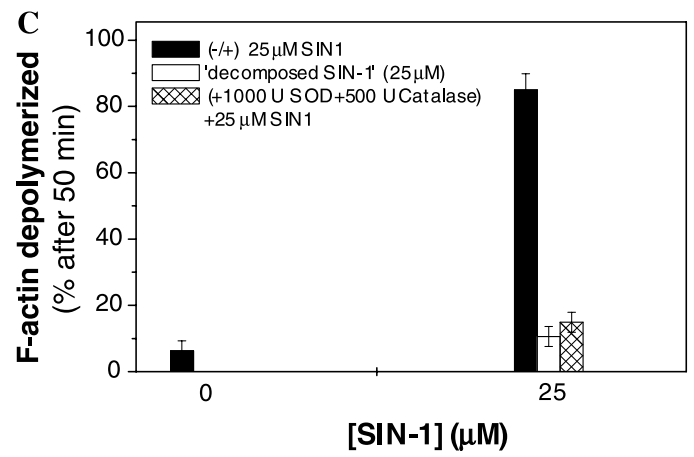

Fig. 1. F-actin depolymerization by peroxynitrite produced during SIN-1 decomposition. Measurements were done as indicated in Materials and methods, with $2 \mu \mathrm{M}$ F-actin. (A) Kinetics of F-actin depolymerization monitored by the decrease of light scattering intensity. Time dependence of the light scattering intensity relative to the intensity at time zero ( $\left.\mathrm{I} / \mathrm{I}_{0}\right)$ after addition of the following SIN-1 concentrations (in $\mu \mathrm{M}$ ): 0 (control, crosses), 2 (open circles), 6.25 (solid circles), 12.5 (open up-triangles), and 25 (solid up-triangles). The intensity signal for G-actin is indicated with an arrow. (B) Dependence upon SIN-1 concentration of the remaining F-actin $2 \mathrm{~h}$ after addition of SIN-1 (i.e., after complete SIN-1 decomposition), calculated from the light scattering intensity readings as indicated in the text. Data (solid squares) are plotted as means $\pm \mathrm{SD}$. (C) F-actin depolymerization is not induced by 'decomposed SIN-1' or by treatment with SIN-1 in the presence of SOD (1000 U) plus catalase (500 U). Extent of F-actin depolymerization 50 min after addition of $25 \mu \mathrm{M}$ SIN-1 (black bars), $25 \mu \mathrm{M}$ 'decomposed SIN-1' (white bars), and $25 \mu \mathrm{M}$ SIN-1 in the presence of SOD plus catalase (stripped bars). The results shown are the average of triplicate experiment.

\section{Differential scanning calorimetry pointed out that} peroxynitrite-induced depolymerization correlated with a structural actin modification that lowers the cooperativity of the unfolding process and also protein thermal stability

F-actin depolymerization by peroxynitrite released upon SIN-1 decomposition can also be monitored by DSC from the decrease of the peak height of the excess heat capacity at the critical unfolding temperature (Fig. 3A), which monitors the decrease of the cooperativity unit of the unfolding process. The F-actin concentration was raised up to $17.2 \mu \mathrm{M}$ to get low noise DSC traces. Again, neither 'decomposed SIN-1' nor treatment with SIN-1 in the presence of SOD plus catalase elicits a significant depolymerization of F-actin. In addition, DSC unraveled that F-actin depolymerization was accompanied by a parallel and large decrease of the thermal stability of F-actin (Figs. 3B and C), with the same $\mathrm{IC}_{50}$ value of $36 \pm 4 \mu \mathrm{M}$ for both processes, which correspond to a peroxynitrite to an actin molar ratio of $2.1 \pm 0.2$, a result very consistent with the result obtained in F-actin depolymerization measurements by light scattering.

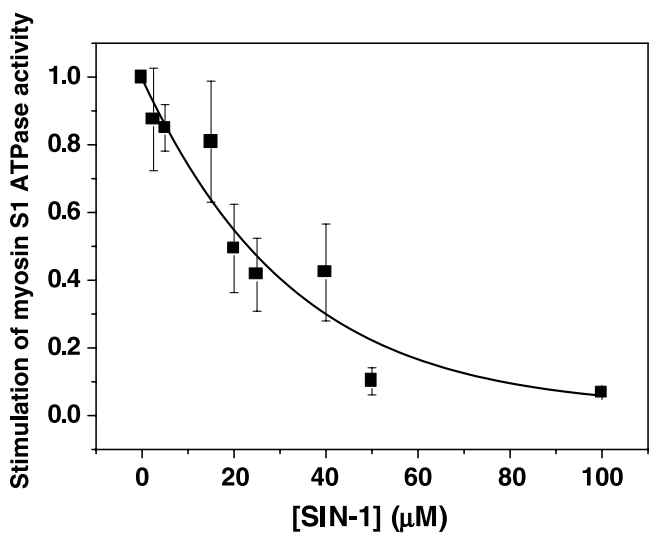

Fig. 2. F-actin treatment with SIN-1 inhibits actin stimulation of S1-myosin ATPase activity. Activity assays were done with F-actin treated for $2 \mathrm{~h}$ with the concentrations of SIN-1 indicated in the abscissa as indicated in Materials and methods. Data (solid squares) are plotted as means $\pm \mathrm{SD}$. The results shown are the average of triplicate experiment.

G-actin polymerization is also impaired upon exposure to submicromolar peroxynitrite fluxes

DSC results pointed out that peroxynitrite-induced F-actin depolymerization is due to the peroxynitrite- 

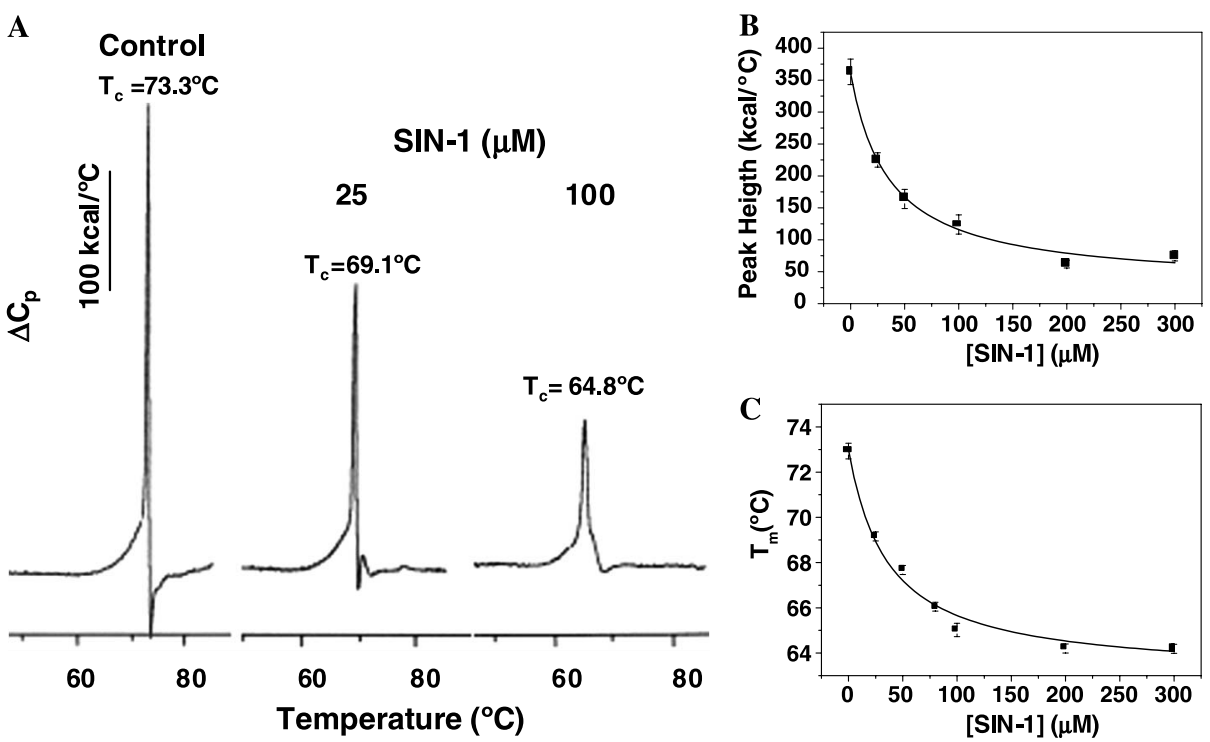

Fig. 3. Treatment with SIN-1 produced decrease of unfolding cooperativity and enhanced thermal unstability of F-actin. DSC experiments were carried out as indicated in Materials and methods, in buffer: $50 \mathrm{mM} \mathrm{Pi}, 10 \mathrm{mM}$ Tris, and $25 \mathrm{mM} \mathrm{KCl}$ (pH 7.35). The traces are representative of experiments done by triplicate with, at least, two different F-actin preparations. (A) DSC traces of F-actin $(17.2 \mu \mathrm{M}$ ) pre-incubated for $2 \mathrm{~h}$ in buffer $10 \mathrm{mM}$ Tris (pH 8.5 ), $25 \mathrm{mM} \mathrm{KCl}$ in the absence (control) or presence of 25 and $100 \mu \mathrm{M} \mathrm{SIN-1} \mathrm{before} \mathrm{loaded} \mathrm{in} \mathrm{the} \mathrm{DSC.} \mathrm{(B)} \mathrm{Dependence} \mathrm{of} \mathrm{the} \mathrm{peak} \mathrm{value} \mathrm{of} \mathrm{excess} \mathrm{heat}$ capacity of the unfolding of F-actin treated with SIN-1 upon the concentration of SIN-1. Data (solid squares) are plotted as means \pm SD. (C) Dependence of the critical unfolding temperature $\left(T_{\mathrm{c}}\right)$ of F-actin treated with SIN-1 upon the concentration of SIN-1. Data (solid squares) are plotted as means \pm SD.

induced structural change on actin molecules. As within cells the level of F-actin is a balance between actin polymerization and depolymerization [4], we measured the effect of G-actin treatment with SIN-1 on the ability of G-actin to form F-actin. The results are shown in Fig. 4 and led to the conclusion that G-actin polymerization is inhibited by SIN-1 with an $\mathrm{IC}_{50}$ value of $10 \pm 1$ and $29 \pm 3 \mu \mathrm{M}$ for the maximum rate and extent of Gactin polymerization, respectively.
Exposure of actin to submicromolar peroxynitrite fluxes produced cysteine oxidation, but not detectable rise of protein carbonyls or of 3-nitrotyrosines

Titration of actin cysteines with DTNB after $2 \mathrm{~h}$ exposure to different SIN-1 concentrations showed a dose-dependent decay of fast-reacting (exposed cysteines) and total actin cysteines (Fig. 5). SIN-1 induced oxidation of actin cysteines and this was also due to released
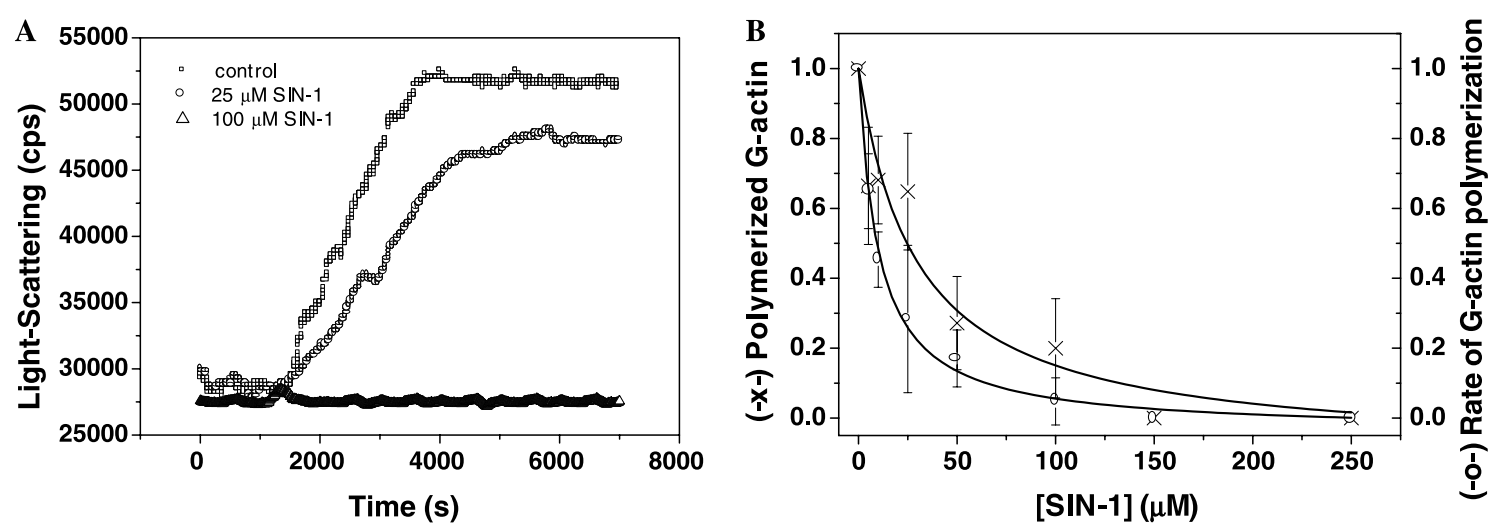

Fig. 4. Treatment with SIN-1 inhibited G-actin polymerization. G-actin $(2 \mu \mathrm{M})$ polymerization was induced by $100 \mathrm{mM} \mathrm{KCl}$ and $2 \mathrm{mM} \mathrm{MgCl}$ at $25^{\circ} \mathrm{C}$. (A) Kinetics of G-actin polymerization in the absence of SIN-1 (open squares) and in the presence of $25 \mu \mathrm{M}$ (open circles) and $100 \mu \mathrm{M}$ SIN-1 (open uptriangles) added to the buffer just before starting the polymerization. (B) Dependence upon SIN-1 concentration of the extent and maximum rate of $\mathrm{G}$-actin polymerization relative to that in untreated G-actin (control). Symbols meaning: $(\times)$ extent of G-actin polymerization after saturation of kinetic traces like those shown in $(\mathrm{A}) ;(\mathrm{O})$ maximum rate of $\mathrm{G}$-actin polymerization obtained from the maximum slope of kinetic traces. The results shown are the average of triplicate experiment. 

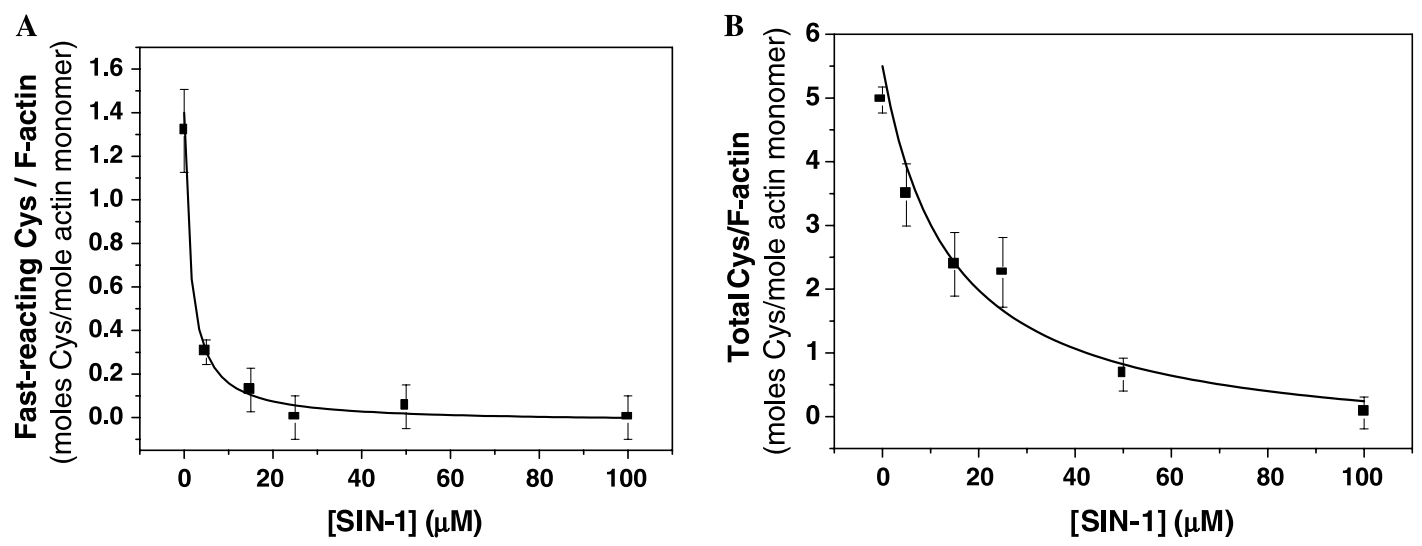

Fig. 5. F-actin cysteine oxidation upon treatment of F-actin with SIN-1. Titration of cysteines was done with $0.1 \mathrm{mM}$ DTNB and $2 \mu \mathrm{M}$ F-actin in $10 \mathrm{mM}$ Tris and $25 \mathrm{mM} \mathrm{KCl}(\mathrm{pH} 8.5)$. The increase in absorbance at $412 \mathrm{~nm}$ was continuously recorded during $10 \mathrm{~min}$, and to measure total cysteines the samples were treated afterwards with $1 \% \mathrm{SDS}$, heated during $5 \mathrm{~min}$ at $80^{\circ} \mathrm{C}$ and the absorbance was measured after cooling during $15-30 \mathrm{~min}$ until reaching a steady value. Cysteines per mole of F-actin monomer were calculated as indicated in Materials and methods. (A) Treatment with SIN-1 produced a dosedependent decrease of F-actin exposed cysteines (i.e., cysteines reacting with DTNB in less than 1 min). Data (solid squares) are plotted as means \pm SD. (B) Treatment with SIN-1 produced a dose-dependent decrease of total F-actin cysteines. Data (solid squares) are plotted as means \pm SD. The results shown are the average of triplicate experiment.

peroxynitrite, because neither 'decomposed SIN-1' nor treatment with SIN-1 in the presence of SOD plus catalase produced significant actin cysteine oxidation, i.e., less than 0.2 cysteines/mole of actin. The $\mathrm{IC}_{50}$ values for SIN-1-induced oxidation of exposed and total F-actin cysteines were $1.5 \pm 0.5$ and $14 \pm 5 \mu \mathrm{M}$ SIN-1, respectively. Bicarbonate $(25 \mathrm{mM})$ did not enhance the effect of SIN-1, therefore, suggesting that peroxynitrite is promoting cysteine oxidation as a directly acting oxidant not through peroxynitrite-derived oxidant radicals, a reaction pathway which is favoured by bicarbonate [25]. This is further supported by the fact that after $2 \mathrm{~h}$ treatment with $10-100 \mu \mathrm{M}$ SIN1 concentrations the levels of protein modifications used as markers of oxidation by peroxynitrite-derived radicals, like 3-nitrotyrosines or protein carbonyls, are not detectable. As it has been shown that actin cysteine oxidation can contribute to the inhibition of actin polymerization as well as to the disruption of actin filaments $[3,4,26]$, these results allow us to rationalize on simple grounds the depolymerization of F-actin induced by peroxynitrite.

\section{Conclusion}

Exposure of $\mathrm{F}$-actin and G-actin to peroxynitrite fluxes of $50-100 \mathrm{nM}$ for $2 \mathrm{~h}$ is sufficient to promote nearly $50 \% \mathrm{~F}$ actin depolymerization and $50 \%$ inhibition of the rate of Gactin polymerization, and peroxynitrite-induced F-actin depolymerization can efficiently block the stimulation of myosin ATPase by actin. These results pointed out that F-actin is between 10- and 20-fold more sensitive to peroxynitrite than other proteins of relevance to muscle bioenergetics reported so far, like creatine kinase [27], myosin [24], and sarcoplasmic reticulum $\mathrm{Ca}^{2+}$-ATPase [21], and point out that actin filaments can be seen as a primary target in the impairment of muscle contraction by oxidative insults promoting a rise of peroxynitrite.

\section{Acknowledgments}

This work has been supported by Joint Spanish-Portuguese Grant HP2004-0080 (to C.G.-M. and M.A.), by POCTI program financed through FEDER for the research project 38191/QUI/2001 (to M.A.), and by Grant 3PR05A078 of the Junta de Extremadura (to C.G.-M.). Dr. T. Tiago is the recipient of a post-doctoral fellowship (SFRH/BPD/20777/2004) from the Portuguese Foundation for Science and Technology (FCT).

\section{References}

[1] M.J. Mihm, F. Yu, C.A. Carnes, P.J. Reiser, P.M. McCarthy, D.R. Van Wagoner, J.A. Bauer, Impaired myofibrillar energetics and oxidative injury during human atrial fibrillation, Circulation 104 (2001) 174-180.

[2] M. Canton, I. Neverova, R. Menabo, J. Van Eyk, F. Di Lisa, Evidence of myofibrillar protein oxidation induced by postischemic reperfusion in isolated rat hearts, Am. J. Physiol. Heart Circ. Physiol. 286 (2004) H870-H877.

[3] A. Milzani, R. Rossi, P. Di Simplicio, D. Giustarini, R. Colombo, I. Dalle-Donne, The oxidation produced by hydrogen peroxide on $\mathrm{Ca}$ ATP-G-actin, Protein Sci. 9 (2000) 1774-1782.

[4] I. Dalle-Donne, A. Milzani, D. Giustarini, P. Di Simplicio, R. Colombo, R. Rossi, S-NO-actin: S-nitrosylation kinetics and the effect on isolated vascular smooth muscle, J. Muscle Res. Cell Motil. 21 (2000) 171-181.

[5] M.J. Eliasson, Z. Huang, R.J. Ferrante, M. Sasamata, M.E. Molliver, S.H. Snyder, M.A. Moskowitz, Neuronal nitric oxide synthase activation and peroxynitrite formation in ischemic stroke linked to neural damage, J. Neurosci. 19 (1999) 5910-5918.

[6] M.J. Mihm, F. Yu, P.J. Reiser, J.A. Bauer, Effects of peroxynitrite on isolated cardiac trabeculae: selective impact on myofibrillar energetic controllers, Biochimie 85 (2003) 587-596.

[7] F. Bao, D. Liu, Peroxynitrite generated in the rat spinal cord induces neuron death and neurological deficits, Neuroscience 115 (2002) 839-849.

[8] M.K. Clements, D.W. Siemsen, S.D. Swain, A.J. Hanson, L.K. Nelson-Overton, T.T. Rohn, M.T. Quinn, Inhibition of actin 
polymerization by peroxynitrite modulates neutrophil functional responses, J. Leukoc. Biol. 73 (2003) 344-355.

[9] J. Kanski, S.J. Hong, C. Schoneich, Proteomic analysis of protein nitration in aging skeletal muscle and identification of nitrotyrosinecontaining sequences in vivo by nanoelectrospray ionization tandem mass spectrometry, J. Biol. Chem. 280 (2005) 24261-24266.

[10] M.P. Murphy, M.A. Packer, J.L. Scarlett, S.W. Martin, Peroxynitrite: a biologically significant oxidant, Gen. Pharmacol. 31 (1998) 179-186.

[11] J.L. Trackey, T.F. Uliasz, S.J. Hewett, SIN-1-induced cytotoxicity in mixed cortical cell culture: peroxynitrite-dependent and -independent induction of excitotoxic cell death, J. Neurochem. 79 (2001) 445-455.

[12] Y. Gutierrez-Martin, F.J. Martin-Romero, F. Henao, C. GutierrezMerino, Alteration of cytosolic free calcium homeostasis by SIN-1: high sensitivity of L-type Ca2+ channels to extracellular oxidative/ nitrosative stress in cerebellar granule cells, J. Neurochem. 92 (2005) 973-989.

[13] M. Kelm, R. Dahmann, D. Wink, M. Feelisch, The nitric oxide/ superoxide assay. Insights into the biological chemistry of the $\mathrm{NO} /$ $\mathrm{O}_{2}{ }^{-}$interaction, J. Biol. Chem. 272 (1997) 9922-9932.

[14] R.E. Huie, S. Padmaja, The reaction of no with superoxide, Free Radic. Res. Commun. 18 (1993) 195-199.

[15] F.J. Martin-Romero, Y. Gutierrez-Martin, F. Henao, C. GutierrezMerino, Fluorescence measurements of steady state peroxynitrite production upon SIN-1 decomposition: NADH versus dihydrodichlorofluorescein and dihydrorhodamine 123, J. Fluoresc. 14 (2004) 17-23.

[16] J.D. Pardee, J.A. Spudich, Purification of muscle actin, Methods Enzymol. 85 (1982) 164-181.

[17] D.J. Gordon, Y.Z. Yang, E.D. Korn, Polymerization of Acanthamoeba actin. Kinetics, thermodynamics, and co-polymerization with muscle actin, J. Biol. Chem. 251 (1976) 7474-7479.

[18] T. Tiago, M. Aureliano, C. Gutierrez-Merino, Decavanadate binding to a high affinity site near the myosin catalytic centre inhibits
F-actin-stimulated myosin ATPase activity, Biochemistry 43 (2004) 5551-5561.

[19] J.A. Cooper, T.D. Pollard, Methods to measure actin polymerization, Methods Enzymol. 85 (Pt. B) (1982) 182-210.

[20] C. Gutierrez-Merino, Gel to liquid crystalline phase transition promotes a conformational reorganization of $\mathrm{Ca} 2+, \mathrm{Mg} 2+$-ATPase from sarcoplasmic reticulum in dimyristoylphosphatidylcholine reconstituted systems, Arch. Biochem. Biophys. 252 (1987) 303-314.

[21] Y. Gutierrez-Martin, F.J. Martin-Romero, F.A. Inesta-Vaquera, C. Gutierrez-Merino, F. Henao, Modulation of sarcoplasmic reticulum $\mathrm{Ca}(2+)$-ATPase by chronic and acute exposure to peroxynitrite, Eur. J. Biochem. 271 (2004) 2647-2657.

[22] I. Dalle-Donne, R. Rossi, D. Giustarini, A. Milzani, R. Colombo, Protein carbonyl groups as biomarkers of oxidative stress, Clin. Chim. Acta 329 (2003) 23-38.

[23] J.M. Merino, C. Gutierrez-Merino, $\mathrm{pH}$ and ligand binding modulate the strength of protein-protein interactions in the $\mathrm{Ca}(2+)$-ATPase from sarcoplasmic reticulum membranes, Biochim. Biophys. Acta 1420 (1999) 203-213.

[24] T. Tiago, S. Simao, M. Aureliano, F.J. Martín-Romero, and C. Gutiérrez-Merino, Inhibition of skeletal muscle S1-myosin ATPase by peroxynitrite, Biochemistry, (2006) in press.

[25] A. Denicola, B.A. Freeman, M. Trujillo, R. Radi, Peroxynitrite reaction with carbon dioxide/bicarbonate: kinetics and influence on peroxynitrite-mediated oxidations, Arch. Biochem. Biophys. 333 (1996) 49-58.

[26] I. Dalle-Donne, R. Rossi, D. Giustarini, N. Gagliano, L. Lusini, A. Milzani, P. Di Simplicio, R. Colombo, Actin carbonylation: from a simple marker of protein oxidation to relevant signs of severe functional impairment, Free Radic. Biol. Med. 31 (2001) 1075-1083.

[27] M.J. Mihm, J.A. Bauer, Peroxynitrite-induced inhibition and nitration of cardiac myofibrillar creatine kinase, Biochimie 84 (2002) 1013-1019. 